\title{
Life cycle optimisation for sustainable algal biofuel production using integrated nutrient recycling technology
}

\author{
Muhammadu Bello $^{\mathrm{a}}$, Panneerselvam Ranganathan ${ }^{\mathrm{b} *}$, Feargal Brennan $^{\mathrm{a}}$ \\ ${ }^{a}$ Energy and Power Division, School of Water, Energy and Environment, Cranfield \\ University, Cranfield, MK43 0AL, United Kingdom. \\ ${ }^{\mathrm{b}}$ Environmental Technology Division, CSIR-National Institute for Interdisciplinary Science \\ and Technology, Trivandrum-695019, India.
}

\begin{abstract}
In this study, a multi-objective optimisation of sustainable integration of algal biofuel production using nutrient recycling technology, such as anaerobic digestion and hydrothermal liquefaction, is considered. Gross annual profitability and Global Warming Potential (GWP) are the criteria chosen for the design of algal biofuel production system. Three scenarios, such as full-scale (baseline), pilot-scale (conservative), and lab-scale (nominal), are chosen based on the expected maturity levels and nutrient demand. The results of the optimisation produce Pareto sets of optimal solutions for acknowledging the trade-off between the economic and the environmental criteria of the integrated system. It is found that the anaerobic digestion (AD) technology shows better performance in terms of environmental perspective and displacing the excessive fertiliser requirements due to its maturity in comparison with hydrothermal liquefaction (HTL) process. However, HTL is a new evolving and promising nutrient recycling technology which demonstrates economic preferences compared to $\mathrm{AD}$ process due to the low cost of production.
\end{abstract}

Keywords: biofuels; anaerobic digestion; hydrothermal liquefaction; life cycle analysis; multi-objective optimisation.

\footnotetext{
${ }^{*}$ Corresponding author. Email address: pranganathan@ @iist.res.in
} 


\section{INTRODUCTION}

There is a continuing interest in considering microalgae as an alternative to traditional energy crops because of their high productivity, faster growth rate, and high photosynthetic efficiency. However, microalgae require more nutrients to achieve high productivity and high oil content compared to the traditional energy crops such as jatropha, oil palm, and rapeseed. ${ }^{1}$ In fact, one of the basic challenges facing the viability of the production and conversion of microalgae to useful products is the resource demands, such as energy, nutrients (including $\mathrm{CO}_{2}$, nitrogen, and phosphorous), and water. Increasing energy and financial return on the investment and reducing the water intensity and nutrient requirement will increase the competitiveness and viability of microalgae-based biofuel system. Therefore, increasing the efficiency of nutrient consumption and nutrient recycling technology is essential for algal biofuel competitiveness in the fuel market. ${ }^{2,3}$ Venteries et al. ${ }^{2}$ reported that approximately 25 million tonnes of nitrogen and 4 million tonnes of phosphorus per annum are needed to be supplied for a large-scale cultivation of microalgae. These requirements are estimated to double the current European Union capacity for fertiliser production if EU substituted all existing transport fuels with algal biofuels. Therefore, the consumption and the amount of these nutrients fully depend on the technology pathway chosen to convert algal biomass to biofuel. The resource demand for a large-scale algal cultivation has always been a concern, and the associated environmental co-benefit is always sought for to ensure sustainability. Various life cycle assessment (LCA) studies have been therefore conducted to analyse the associated implications of nutrient demand on the economic and environmental issues of commercial-scale microalgae cultivation. ${ }^{4-10}$ Venteries et al. ${ }^{2}$ and Wigmosta et al. ${ }^{11}$ investigated the nutrient supply and resource sustainability for Chlorella growth and compared various technologies and their impact on the optimisation of algal biofuel production. Pate et al. ${ }^{12}$ and Quinn et al. ${ }^{13}$ conducted a regional-scale resource analysis of 
open pond system and site-specific analysis for photo-bioreactor and concluded that the resource sustainability is potentially a serious limitation for a successful deployment of the algal biofuel industry. Gutiérrez-Arriaga et al. ${ }^{14}$ conducted a multi-objective optimisation on the profitability and environmental impact of the algal biodiesel production coupled with the steam electric power plant. However, the system integration and optimisation of nutrient recycling technologies with algal biofuels have not been studied so far in the literature. The integration of nutrient recycling technology, such as AD or HTL, with the algal biofuel system can be a great potential to offset the excessive nutrient demand for continuous algae culturing. The nutrient recycling technology of HTL yields a product typically refers to biocrude along with gas, liquid, and solids (char) streams. Both char and bio-crude can be combusted to generate heat, while nutrient-rich liquid stream can be recycled into the algal culture. ${ }^{15}$ Thus, HTL process has an additional benefit of energy recovery and nutrient recycling capability. However, the amount of energy recovered depends on HTL process and operating conditions, such as the temperature, pressure, microalgae composition, retention time, and catalyst used.

On the other hand, $\mathrm{AD}$ is a matured process for microalgae conversion, and it finds application in many commercial and industrial processes. The effluent from the digester is referred to the digestate which contains a highly rich nutrient that can potentially be recycled to the algal pond for cultivation. ${ }^{16-18}$ The liquid fraction of the digestate contains more than $60 \% \mathrm{~N}$ after solid-liquid separation, and the solid digestate is normally used for soil amendment's purpose. ${ }^{18} \mathrm{AD}$ process can be used to convert the residual biomass (after the lipid extraction) as well as nutrient recycling of nitrogen and phosphorous for culturing microalgae. The theoretical methane production in the AD process from lipid extracted algal biomass produces more energy than that obtained from the lipid conversions. It depends on 
the gross composition of the residual biomass, retention time, temperature, and loading rate. It can be estimated based on volatile solids (VS) and the biodegradation rate. ${ }^{17-19}$ Therefore, there is a considerable benefit of energy and nutrient recovery from these technologies which may induce the lower GHG emissions and possibility of cost reduction. Despite the aforementioned potentials, no systematic investigation has so far conducted, specifically on the integration of nutrient recycling technology with algal biofuel production, focussing on the economic and environmental sustainability. Although various stand-alone life cycle studies in the view of techno-economic feasibility and the environmental impacts of different algal culturing and processing have conducted in the literature ${ }^{4,6-10}$, the sustainability of algal biofuel production with integrating nutrient recycling technology through optimisation studies needs to be carried out.

This study intends to examine the integration of nutrient recycling technologies, such as anaerobic digestion (AD) or hydrothermal liquefaction (HTL), with biofuel production from microalgae. We investigate nutrient recycling capability, profitability, and sustainability of integrating AD or HTL with algal biofuel production using multi-objective optimisation technique.

\section{MATERIALS AND METHODS}

Mathematical models entailing energy and mass balances based on LCA methodology coupled with the optimisation technique of Genetic Algorithm (GA) are employed in this study.

\section{System description}

A schematic algal pond is represented as shown in Figure 1 to depict the hypothetical integrated biofuel production system from microalgae. A bio-refinery process model is considered for sustainable production of lipids for biodiesel and co-generation of heat and 
electricity by different nutrient recycling technology. Microalgae are to be cultivated in an open pond, harvested in settling tanks using auto-flocculation, flocculated with chemicals (Chitosan), collected by dissolved air flotation, concentrated by centrifugation/drying and extracted using solvent (hexane) extraction methodology. The algal system is modelled as a commercial-scale of 100 ha open raceway pond system used to cultivate microalgae. This scale of operation has been already studied in the literature. ${ }^{20}$ The pond design is assumed with industrial standards ${ }^{5}: 150 \mathrm{~m}$ long, $10 \mathrm{~m}$ wide and $0.3 \mathrm{~m}$ depth, and the mixing velocity of $0.2 \mathrm{~m} / \mathrm{s}$ by the paddle wheel. The pond system is assumed to operate 360 days. The system is assumed to progress with a steady state concentration of $0.5 \mathrm{~g} / \mathrm{l}$ in the pond and $200 \mathrm{~g} / \mathrm{l}$ of the harvested algae for the production of biofuel. The algal productivity yield is used in the range of $25-40 \mathrm{~g} /\left(\mathrm{m}^{2}\right.$ day $)$ in this study. Various other parameters used in system analysis are listed in Table 1. The detailed descriptions and the assumptions used in the integrated microalgae biofuels products using AD/HTL resource recycling technology can be obtained in the supplementary data.

Residues after oil extraction are digested using anaerobic digestion (AD) for energy recovery and nutrient recycling. An alternative nutrient recycling technology scenario considers hydrothermal liquefaction (HTL). The nutrient rich liquid stream from either AD/HTL is recycled back into the cultivation pond to replenish the demand of fertiliser. ${ }^{21}$

If $\mathrm{AD}$ is implemented for energy recovery and nutrient recycling, the biogas is combusted in a gas turbine CHP (combined heat and power generator) unit with an electricity conversion efficiency of $36 \%$ and heat generation efficiency of $50 \%$. While if HTL is used, the biocrude and char produced would be combusted in a boiler and converted to power and heat in a steam turbine CHP unit (9\% electricity efficiency and $70 \%$ heat efficiency) as described by Zhang et al. ${ }^{21}$. Higher yields in HTL are associated with higher temperature, ranges below $360^{\circ} \mathrm{C}^{21}$ The HTL product yields of bio-crude, gas, liquid and solid consist of $36 \%, 40 \%$, 
$17 \%$ and $7 \%$, respectively. ${ }^{22}$ The previous studies have shown that more than $70 \%$ of $\mathrm{N}$ and approximately $30 \%$ of P remain in the liquid stream of the HTL product. ${ }^{23-25}$ The energy products of the microalgae residue from both AD and HTL are combusted in gas turbine/steam turbine to produce heat and electricity respectively to meet some internal heat and power demands of the system, while other demands are considered to be met by natural gas used in a CHP unit or boiler for heat and electricity based on the grid. ${ }^{14,21}$ In short, heat is used in the extraction, digester, and drying processes, while electricity is utilised for on-site electricity demand, such as dewatering process.

To assess the environmental and cost implication of nutrient demand of the microalgae biofuel system using the potential of nutrient recycling technology, such as AD and HTL, three different scenarios or levels are considered in this study. The chosen scenarios are assumed to be illustrative rather than a representation of actual or any particular technology selection. The full-scale scenario (baseline) represents the maximum productive scenario using matured technologies. This scenario is a representation of large-scale microalgae to biofuel production system at the near term, where a significant amount of engineering is required to realise these values. The pilot-scale scenario (conservative) represents technology that has been demonstrated at pilot-scale and the readiness of existing nutrient recycling technologies is fully demonstrated with the maximum resource consumption efficiency obtainable. The lab-scale scenario (nominal) is used to understand how microalgae-toenergy production would fare if the operating parameters including growth rates, conversion efficiencies and other relevant parameters that have been achieved at lab-scale.

In a full-scale scenario, most of the required input parameters are based on the projections from field data on energy efficiencies and yields for coming 5 years. The pilot-scale scenario is based on the data that was reported in the literature which is mostly obtained from the existing pilot-scale operation. The lab-scale scenario is mainly based on the variety of 
published sources in the literature and using these types of data, most of the previous LCA studies are performed. In this work, the assumed model parameters for each scenario and data sources can be found in Table 1.

\section{Mathematical model formulation}

A multi-objective optimisation for sustainable design of the algal biofuel system using nutrient recycling technology is considered in this work. The mathematical models are presented here as the linear algebraic equations in which a bi-criteria optimisation is proposed using four different types of constraints namely: (i) mass balance equations; (ii) energy balance constraints; (iii) economic analysis constraints; and (iv) environmental analysis constraints. These constraints are used for multi-objective modelling of the hypothetical microalgae biorefinery using two different nutrient recycling technologies. Profitability is the economic objective function that is intended to be maximised. The minimisation objective function is labelled as the global warming potential (GWP) to carefully facilitate the optimal design and operation of the hypothetical commercial-scale microalgae biofuel production system. The details of mass and energy balance constraints used in this study are presented in the supplementary material.

\section{Economic analysis}

The annual gross profit is an impact criteria as well as an objective function used in this study to measure the economic sustainability metric of the microalgae biofuel production at the preliminary design stage. The profitability is a simply defined as the revenue obtained from the sale of electricity, biodiesel, and glycerol plus the total subsidy (Tax credit) obtained from the GHG reductions (by the displacement of fertiliser inputs and assuming natural gas in a boiler and electricity from the grid) minus the total annualised cost (TAC). This can be written as

$$
\text { Profit }=\text { Revenue }+ \text { Tax credit }- \text { TAC }
$$


The revenue is obtained from selling the products of the hypothetical bio-refinery, which includes biodiesel, electricity, glycerol, and the co-products of nutrients recovered from the nutrient recycling technology as follows:

$$
\text { Revenue }=P_{E L E C} * E L E C_{T}+P_{B D} * F_{B D}+P_{G L Y} * F_{G L Y_{N_{T}}}
$$

where $P_{E L E C}, P_{B D}, P_{G L Y}, P_{N_{T}}$ are the unit selling prices of electricity, biodiesel, and glycerol respectively and these values are taken from the literature. ${ }^{26} E L E C_{T}$ is the net electricity generated per year and the subscript " $T$ " is the resource recycling technology. $F_{B D}$ and $F_{G L Y}$ are the flow rates of biodiesel and glycerol, respectively.

The total annualised cost (TAC) can be expressed as the sum of the annual capital cost $\left(\mathrm{TC}_{F}\right)$ and annual operating cost $\left(\mathrm{TC}_{O}\right)$

$$
\mathrm{TAC}=\mathrm{TC}_{F}+\mathrm{TC}_{O}
$$

The annual capital cost is determined as the sum of the equipment purchase cost of each unit involved in the integrated biorefinery system. The equipment purchase cost of unit is calculated using the correlation given by Gebreslassie et $\mathrm{al}^{26}$. The annual operating cost associated with the raw materials and nutrients is taken from the various sources in the literature. $^{26,27}$

The economic performance objective function (profit) of the hypothetical commercial system is represented as follows:

$$
\operatorname{Max}_{x} \text { Profit }
$$

Subject to $h_{i}(x, \mathrm{y})=0, \mathrm{i}=1, \ldots \ldots, \mathrm{m}$

$$
g_{i}(x, \mathrm{y}) \leq 0, \mathrm{i}=1, \ldots \ldots, \mathrm{l}
$$

The equality constraints represent the performance of the system, such as the energy and mass balances and are illustrated as $h_{i}(x, y)=0$. The inequality constraints $\left(g_{i}(x, y) \leq 0\right)$ explain the minimum and maximum process variables in terms of energy requirements, material availabilities, and capacities. The decision variables, $x$ are continuous and they 
correspond to the resources and energy flows, the compositions, the size of process units, pressures, and temperatures, etc., while $y$ is the output measurements of the system.

\section{Environmental analysis}

LCA is a systematic analytical method for evaluating energy flows and environmental effects of processes and their impacts along its life cycle. It follows a series of standards of (i) goal and scope definition, (ii) inventory analysis, (iii) impact assessment, and (iv) interpretation.

\section{Goal and scope definition}

The overall environmental objective of this study is to minimise the entire GHG emissions related to the hypothetical commercial-scale biofuel production that uses different types of (AD/HTL) nutrient recycling technology. The hypothetical biorefinery is a multi-output system where electricity, biodiesel, and glycerol are outputs, while the nutrient recycled is traded as organic fertiliser and energy source. The functional unit of MJ of biodiesel produced is chosen for this study. This type of functional unit has been used previously in the literature. ${ }^{7,36}$ The system boundary of the hypothetical algal production system is depicted in Figure 2.

A cradle-to-gate analysis is considered in this study that entails emissions of $\mathrm{CO}_{2}, \mathrm{NO}_{\mathrm{x}}$, and $\mathrm{CH}_{4}$ during nutrient recovery from AD/HTL, heat and electricity consumptions, and emissions associated with the natural gas acquisitions coupled with direct emissions from algae growth to biodiesel production. The environmental impact investigated in this study is global warming potential (GWP) which is expressed in $\mathrm{CO}_{2}$ equivalent emissions per $\mathrm{MJ}$ of biofuel produced. ${ }^{37}$ In this work, the substitution is used for system allocation. In which, the lipid extracted algae (algae residue) that produces energy by AD/HTL which replaces heat and electricity requirement of the integrated process. Net energy produced from the integrated system using AD/HTL resource technology is a co-product of electricity. 
Regarding co-product of glycerol, it would be difficult to make allocation by substitution. Therefore, allocation by market price is considered in this work.

Inventory analysis

In this step, inventory of input /output data of the hypothetical bio-refinery, including $\mathrm{AD} / \mathrm{HTL}$ process, is conducted based on mass and energy balances. The life cycle inventories of emissions as output data, such as emissions from heat and electricity, and processing unit operations, are recorded for every input, such as the flow rates of the species, nutrients, and water. The consumption rates of energy products are obtained from the literature ${ }^{14}$ and environmental databases in SimaPro. ${ }^{38}$

\section{Impact assessment}

In this stage, the life cycle inventory emissions are aggregated into a single environmental metric to quantify the potential environmental impact. The environmental metric used in this step is GWP which is employed to determine the environmental performance of the hypothetical microalgae bio-refinery system. It is calculated based on the overall GWP from emissions related to heat and electricity consumptions and direct emissions from the operations of the hypothetical microalgae bio-refinery. Moreover, the damage factors are employed to connect the GWP with the GHG emissions from the hypothetical algal biorefinery with AD/HTL systems. These values are retrieved from specific environmental models such as the Intergovernmental Panel on Climate Change (IPCC) with characterisation factors of a 100-year horizon (GWP 100a). ${ }^{37}$

Life cycle GHG emissions reduction of the hypothetical commercial-scale algal biofuel facility can be calculated using a reference system of the same amount of heat and power produced and assuming a displacement scenario where heat requirements for biofuel production come from the combustion of natural gas in a boiler and electricity comes from the grid. ${ }^{15}$ Same scenario is applicable to the nutrient recycled by the AD/HTL process to 
displace the fertiliser inputs. Thus, GHG emissions reduction (GHGred ${ }_{A D}^{\text {elec }}$ ) by electricity generation from $\mathrm{AD}$ can be calculated as follows:

$$
\text { GHGred }_{A D}^{\text {elec }}=\mathrm{E}_{A D}^{\text {elect }} * E M_{\text {elec }}^{L C A}(5)
$$

where $E M_{\text {elec }}^{L C A}$ is the life cycle GHG emission factor of average electricity generated in a particular region and $E_{A D}^{\text {elect }}$ is the rate of electricity produced by AD process. Similarly, GHG emissions reduction by electricity from HTL $\left(\right.$ GHGred $\left._{H T L}^{e l e c}\right)$ can be determined as follows:

$$
\mathrm{GHGred}_{H T L}^{\text {elec }}=\mathrm{E}_{H T L}^{\text {elect }} * E M_{\text {elec }}^{L C A}(6)
$$

Assuming heat requirements for the biofuel production come from $\mathrm{AD}$, the GHG emissions reduction can be determined based on the boiler efficiency as follows:

$$
\mathrm{GHGred}_{A D}^{\text {heat }}=\frac{\mathrm{E}_{A D}^{\text {heat }}}{\partial_{b}} * E M_{N G}^{L C A}
$$

where $\partial_{b}$ is the boiler efficiency, $E_{A D}^{\text {heat }}$ is the rate of heat generated from $\mathrm{AD}$, and $E M_{N G}^{L C A}$ is the life cycle GHG emission factor of natural gas. Similarly, life cycle GHG emissions reduction in terms of fertiliser inputs of both $\mathrm{N}$ and $\mathrm{P}$ from $\mathrm{AD} / \mathrm{HTL}$ process $\left(\mathrm{GHGred}_{T P W}^{M}\right)$ can be calculated as follows:

$$
\operatorname{GHGred}_{T P W}^{M}=N U T_{T P W}^{M} * E M_{M, T P W}^{L C A}
$$

where $N U T_{T P W}^{M}$ is the nutrient demand efficiency, $M$ represents nitrogen or phosphorous resource and TPW stands for technology pathways (AD or HTL).

The tax credit of the hypothetical microalgae biofuel system can be calculated as follows:

$$
\begin{gathered}
\text { Tax credit }=S^{g h g}\left(\text { GHGred }_{A D}^{\text {elec }}+\text { GHGred }_{H T L}^{\text {elec }}+\text { GHGred }_{A D}^{\text {heat }}\right. \\
\left.+ \text { GHGred }_{T P W}^{M}\right)
\end{gathered}
$$

where $S^{g h g}$ is the unit subsidy for reduction of life cycle GHG emissions in \$/ton of GHG reduced. 
Now, the GWP potentials can be easily classified into three subcategories viz: (i) GWP direct emissions from energy and fertiliser inputs; (ii) GWP power consumptions emissions from the unit operations of the hypothetical bio-refinery; and (iii) GWP emissions from heat consumptions associated with the unit operations of the algae bio-refinery.

\section{GWP direct emissions}

Direct emissions are related to energy and fertiliser inputs for the nutrient and energy requirements of the microalgae biofuel system and these emissions are computed as follows:

$\mathrm{GWP}_{D I R E C T}=\theta_{D}\left(\mathrm{GHGemi}_{A D}^{\text {elec }}+\mathrm{GHGemi}_{H T L}^{\text {elec }}+\mathrm{GHGemi}_{A D}^{\text {heat }}+\mathrm{GHGemi}_{T P W}^{M}\right)$

where $\theta_{D}$ is the damage factor that accounts for the GWP associated with the direct emissions related to $G H G_{D I R E C T}$.

GWP power consumption emissions

GWP associated with the power consumptions of various unit operations in the hypothetical bio-refinery and the nutrient recycling technology, such as growth pond, pumps, harvesting units, dewatering units, lipid extraction units, AD units, and HTL units is calculated based on the following equation:

$$
\mathrm{GWP}_{P C}=\theta_{P C} \sum_{K} P C
$$

where $\theta_{P C}$ is the damage factor that accounts for the GWP associated with the power generation and $P C$ is the power consumptions of the various and distinctive unit operations.

\section{Algae bio-refinery unit heat consumption emissions}

The heat consumptions associated with various unit operations in the nutrient recycling technology and the hypothetical bio-refinery is calculated using the following equation:

$$
\mathrm{GWP}_{H C}=\theta_{H} \sum_{K} H C(12)
$$

where $\theta_{H}$ is the damage factor that accounts for the GWP associated with the heat generation and $H C$ is the heat consumptions of the various operations. 


\section{Environmental objective function}

The overall GWP is the summation of the various GWP contributions obtained from direct emissions, power, and consumptions of the algae bio-refinery as:

$$
\mathrm{GWP}_{\text {OVERALL }}=\sum_{K} G W P_{K}
$$

where $k$ represents all the GWP from the direct emissions, power, and heat consumptions.

Now, the environmental objective function of the hypothetical system is obtained as follows:

$$
\begin{aligned}
& \operatorname{Min}_{x} G W P \\
& \text { Subject to } h_{i}(x, \mathrm{y})=0, \mathrm{i}=1, \ldots \ldots, \mathrm{m} \\
& g_{i}(x, \mathrm{y}) \leq 0, \mathrm{i}=1, \ldots \ldots, \mathrm{l}
\end{aligned}
$$

where GWP represents the environmental performance objective function of the system. The continuous variable, $x$ represents decision variable which corresponds to the resources and energy flows, heat and power consumptions, the size of process units, pressures, temperatures, life cycle emissions inventory, and direct emissions etc., while $y$ is the output measurement of the system. The equality constraints represent the performance of the system, such as the energy and mass balances, cost, and LCA constraints and are illustrated as $h_{i}(x, y)=0$. The inequality constraints $\left(g_{i}(x, y) \leq 0\right)$ explain the minimum and maximum process variables in terms of energy requirements, material availabilities, and capacities.

\section{Interpretation}

In this work, a genetic algorithm (GA) is used to implement the multi-objective optimisation study. GA is more robust and a stochastic search method. It involves the search of a random set of populations rather a single point which results in much better solutions. Most important feature of GA, especially in terms of multi-objective optimisation, is the ability to converge on the Pareto-optimal sets for a highly, non-convex problems. Pareto-optimal sets showing 
distinctive and alternative designs can be obtained during the optimisation process. Moreover, in all the observed Pareto-curves, each point represents an optimal design condition.

\section{RESULTS AND DISCUSSION}

\section{Effect of nutrient recycling technology}

Mathematical models entailing mass and energy balances coupled with the optimisation described in the previous section were solved using Genetic Algorithm (GA) technique in MATLAB tool. The population size of 300 chromosomes and the crossover fraction of 0.7 were used. In this work, GWP is represented as in term of the functional unit of $\mathrm{g} \mathrm{CO}_{2}$ eq. per MJ of biodiesel produced whereas profit is represented as annually. The annual gross profit is used for economic function due to several potential co-products in addition to biodiesel namely, glycerol and electricity. Table 2 shows the modelling results of the annual profit and GWP with a subsidy unit of $20 \mathrm{US \$ /tonne} \mathrm{of} \mathrm{CO}_{2}$ eq. for various scenarios using different recycling technologies (AD/HTL). It can be seen from the table that a full-scale scenario in both AD and HTL shows the larger the value of the profitability. It is also observed that in the AD case, even though the profitability increases from lab-scale scenario to full-scale scenario, GWP increases from lab-scale scenario to pilot-scale scenario and then decreases from pilot-scale scenario to full-scale scenario. However, in the HTL, the different trend is observed, i.e., the profitability increases, while the GWP decreases from lab-scale scenario to full-scale scenario. Notwithstanding these differences, the profitability of both processes is optimistic and tight to the unit of subsidies incorporated in the system. Figures $3(\mathrm{a}-\mathrm{c})$ illustrate the solution of the multi-objective problem, providing Pareto curves for the integrated hypothetical biofuel system with different scenarios of AD recycling technology. The Pareto curves represent the best possible trade-off between the annual gross 
profit and GWP of the hypothetical system. The simulation is performed using different unit subsidies for the reduction of GHG emissions. A range of 20-60 US\$/tonne $\mathrm{CO}_{2}$ eq. subsidy rate is used for observing the profitability and GWP behaviours of the hypothetical system. The figures illustrate that the reduction in the GWP using different unit subsidies can be achieved at the expense of a decrease in the venture profitability. In a full-scale scenario with a subsidy unit of $20 \mathrm{US} \$ /$ tonne $\mathrm{CO}_{2}$ eq., point A corresponds to the most environmentally sustainable solution, with the lowest GHG emission of $46 \mathrm{~g} \mathrm{CO}_{2}$ eq./MJ but the annual profit is almost zero. On the other hand, point $\mathrm{C}$ corresponds to the most economical solution, with the highest $\mathrm{GHG}$ emission of $60 \mathrm{~g} \mathrm{CO}_{2}$ eq./MJ and the highest annual profit of US\$3.6 MM. Considering the trade-off between the economic and environmental criteria, we identify point $\mathrm{B}$ with the $\mathrm{GHG}$ emission of $53 \mathrm{~g} \mathrm{CO}_{2}$ eq./MJ and the annual profit of US\$3.4 MM as a good choice, which significantly reduces the cost involving in the GHG emission. However, it is worth to mention that all the solutions on the Pareto curve are considered Pareto-optimal where the gross profit is maximised with respect to the specified GWP limit, among which one can choose for the supply chain design according to the preference. Solutions in the region above the curve are not feasible whereas solutions in the region below the curve are suboptimal.

It is also shown in Figure 3 that the larger unit subsidy rate for reduction of GHG emissions, more gross profit can be achieved. The higher profitability is associated with the production of biodiesel from microalgae inducing the higher revenue generation as well as the impact of high nutrient recycle rates on biodiesel yield. This is because high nutrient increases the revenue and thus reduces operating cost, thereby avoiding direct GHG emissions from fertiliser production. Similarly, the higher the global warming potential the higher the profitability. This is because the higher global warming potential is associated with heat and power consumptions which have the direct impact on the capacity of the hypothetical bio- 
refinery to produce more biofuel. A value of GWP obtained in this study is $60 \mathrm{~g}$ of $\mathrm{CO}_{2}$ eq. /MJ with the annual profit of US\$3.6 MM and its corresponding annualised cost of US\$1.6 per Gasoline Gallon Equivalent (GGE). This range of result is comparable with the previously reported work in the literature. ${ }^{39}$ Gong and You ${ }^{39}$ investigated sustainable design and synthesis of manufacturing algal products from microalgae including biodiesel, and value added biochemicals. Their optimisation results indicate that the algal biorefinery can achieve a unit annualised cost of $\$ 2.78 / \mathrm{GGE}$ and unit of $61 \mathrm{~g}$ of $\mathrm{CO}_{2}$ eq./MJ biodiesel produced. Thus, the results obtained in this work show that the integrated biorefinery system could be profitable.

Figures 4(a,b) show Pareto curves for integrated biofuel system using different scenarios of $\mathrm{AD}$ recycling technology at a subsidy unit of 20 and $40 \mathrm{US} \$ /$ tonne $\mathrm{CO}_{2}$ eq.. The results indicate that the increasing annual gross profit is observed when the scenario changes from the lab-scale to pilot-scale and from pilot-scale to full-scale. This may be due to the amount of nutrients that can be recycled back to the pond depends on the scenario and thus offset by the energy products produced from AD. The baseline scenario (full-scale) that uses the high rates of nutrient recycled (the high maturity of nutrient recycling technology) shows the highest maximum gross profit. The results also indicate that the pilot-scale scenario shows greatest GWP in the range of $58-70 \mathrm{~g}$ of $\mathrm{CO}_{2}$ eq./MJ in a comparison with lab-and full-scale scenarios which observe in the range of 40 to $45 \mathrm{~g}$ of $\mathrm{CO}_{2}$ eq./MJ and 45 to $60 \mathrm{~g}$ of $\mathrm{CO}_{2}$ eq./MJ respectively. The higher GWP in both pilot- and commercial-scales may be because of high energy use. The higher energy demand in pilot-and commercial-scales may be due to low nutrient recycling efficiency and consequently lower production of biogas. A similar finding has been reported by Liu et al. ${ }^{36}$. The authors found that the GHG emission is higher for pilot-scale scenario than that in full-scale and lab-scale scenarios in the case of algaederived diesel fuel. In fact, the higher the system's efficiency the lower the GWP and this 
largely depends on the efficiency of distinctive algal production units such as growth, harvesting, dewatering, conversion units etc., and their GWP values. This is also largely influenced by the energy consumption which directly depends on the material inputs coupled with the auxiliary input energy provided. The discrepancy that occurs in the GWP could also be attributed to the fact that algal biofuel process is still at the infancy stage and the extrapolation of data obtained from the well-controlled laboratory to pilot- and commercial-scale is very difficult and complex.

Figures $5(\mathrm{a}-\mathrm{c})$ represent the solution of the multi-objective problem providing Pareto curves for integrated hypothetical biofuel systems with different scenarios of HTL recycling technology. It is found that the higher the profitability the higher GWP. Also, it is observed that the profitability increases, while the GWP decreases when the scenario changes from lab-scale to the full-scale scenario. This may be because the energy use and GHG emissions are higher when the scenario changes from full-scale to lab-scale due to its low-biocrude yield and nutrient recycling efficiency in HTL. Also, when the scenario changes from labscale to commercial-scale, a significant improvement in all criteria leads to the decrease in energy demand which results in the reduction in the GWP.

The value of GWP obtained in this study is $31 \mathrm{~g}$ of $\mathrm{CO}_{2}$ eq. $/ \mathrm{MJ}$ with the annual profit of US\$ 2.3 MM and its corresponding annualised cost of US\$0.9 per Gasoline Gallon Equivalent (GGE). This range of GWP is comparable with the previously reported work of Lio et al. ${ }^{36}$. The authors reported GWP for full-scale algae-derived fuel by HTL process approximately $30 \mathrm{gCO}_{2}$ eq. $/ \mathrm{MJ}$ of biofuel produced.

\section{Comparison between HTL and AD}

A comparison plot of Pareto curves between AD and HTL recycling technology for different scenarios at a particular subsidy unit of $20 \mathrm{US} \$ /$ tonne $\mathrm{CO}_{2}$ eq. is shown in Figure 6a. It is found that the profitability of the AD nutrient recycling technology for both full-scale and 
pilot-scale scenarios is greater than that of HTL recycling technology at the expense of higher GHG emissions. A full-scale scenario of HTL nutrient recycling technology shows the annual profit of US\$2.3 MM at GWP of $31 \mathrm{~g} \mathrm{CO}_{2}$ eq. per MJ of biofuel produced, whereas full-scale scenario of AD recycling technology shows the annual profit of US\$3.6 $\mathrm{MM}$ at GWP of $60 \mathrm{gCO}_{2}$ eq. per MJ of biofuel produced. Similarly, a pilot-scale scenario of HTL nutrient recycling technology shows the profit of US\$1.1 MM at GWP of $45 \mathrm{~g} \mathrm{CO}_{2}$ eq. per MJ of biofuel produced, whereas pilot-scale AD shows the profit of US\$1.8 MM at GWP of $70 \mathrm{gCO}_{2}$ eq. per MJ of biofuel produced. The lab-scale scenario of HTL shows slightly better than that of $\mathrm{AD}$, i.e., HTL shows the annual profit of US\$0.5 MM at GWP of $55 \mathrm{gCO}_{2}$ eq. per MJ, whereas AD shows the annual profit of US\$0.3 MM at GWP of $47 \mathrm{gCO}_{2}$ eq. per MJ. The higher profit in lab-scale HTL may stem from the bio-crude yield and the lower production cost of the HTL process compared to the methane production in the AD process. Recently, Delrue et al. ${ }^{40}$ compared the residue upgraded process of HTL with the AD process and reported that the production cost is significantly lower for the HTL (average 52.7£/GJ.) than that of AD (average 74.8£/GJ.). However, the distinctive solutions involved in either AD or HTL scenario are a clearly different trade-off between profitability and GWP in which one can make a choice and decide on a particular solution that is determined based on the preferences at a particular point in time.

A comparison between $\mathrm{AD}$ and HTL in terms of nutrient recycling, energy production and GHG reduction behaviours for the hypothetical integrated biorefinery system with baseline scenario is shown in Table 3. 2.94 tonnes/year $\mathrm{N}$ and 4.7 tonnes/year $\mathrm{P}$ can be recycled from AD, whereas from HTL 1.08 tonne/year N and 1.1 tonnes/year P can be recycled. AD has a higher recycling rate compared to HTL. In terms of the total energy production and consumption in AD and HTL nutrient recycling technology, AD produces more energy $\left(1.1691 \times 10^{8} \mathrm{MJ} /\right.$ year) than HTL does $\left(8.9729 \times 10^{7} \mathrm{MJ} /\right.$ year $)$, whereas HTL consumes more 
power $\left(8.7042 \times 10^{7} \mathrm{MJ} / \mathrm{year}\right)$ than $\mathrm{AD}\left(6.6913 \times 10^{7} \mathrm{MJ} /\right.$ year $)$. HTL produces a lower amount of electricity $\left(1.019 \times 10^{7} \mathrm{MJ} /\right.$ year $)$ due to low electricity conversion efficiency of the steam turbine CHP unit while it produces more heat $\left(7.926 \times 10^{7} \mathrm{MJ} /\right.$ year). Since AD generates more both electricity $\left(4.241 \times 10^{7} \mathrm{MJ} /\right.$ year $)$ and heat $\left(5.89 \times 10^{7} \mathrm{MJ} /\right.$ year $)$ due to the higher conversion efficiency of gas turbine CHP unit, it has the higher capability for energy recycling to the integrated bio-refinery system. Total GHG reduction by AD and HTL recycling technology are also shown in Table 3 . The GHG reduction from recycling $\mathrm{N}$ and $\mathrm{P}$ is 4.59 and $0.49 \mathrm{gCO}_{2}$ eq. per $\mathrm{MJ}$ of biofuel produced by $\mathrm{AD}$ and 4.57 and $0.47 \mathrm{gCO}_{2}$ eq. per MJ of biofuel produced by HTL. The GHG reduction from avoiding electricity from the grid and heat from $\mathrm{NG}$ combustion in the boiler is 53.79 and $33.9 \mathrm{gCO}_{2}$ eq. per MJ of biofuel produced by $\mathrm{AD}$ and 12.93 and $45.61 \mathrm{gCO}_{2}$ eq. per $\mathrm{MJ}$ of biofuel produced by HTL. Both AD and HTL shows a similar range of GHG reduction from nutrient recycling. However, AD shows an overall higher GHG reduction than that from HTL. The energy return on investment (EROI= net energy produced/net energy input) and GWP ( $\mathrm{gCO}_{2}$ eq./MJ of biofuel produced) of the integrated energy system involving AD and HTL nutrient recycling technology for various scenarios are also calculated and these values are shown in Fig 6b. The results show that the integrated energy system involving HTL nutrient recycling has a lower EROI in the range of 1.1 for all three scenarios in comparison with the AD recycling technology which has a higher EROI, approximately 2.0. The process will generate more energy when EROI value is greater than 1. These results are in the similar range reported by Lio et al. ${ }^{36}$ The authors found that the EROIs for full-scale algae-derived fuel and pilot scale algae-derived fuel by HTL process are approximately 2.5 and 1 respectively. GWP for HTL nutrient recycling technology shows lower than AD technology. However, both AD and HTL nutrient recycling technology shows lower GWP compared to fossil fuel which emits considerably more GHGs $(94.3 \mathrm{~g} \mathrm{CO} 2 / \mathrm{MJ}) .^{36,41}$ 
Based on this finding, AD technology is much better in terms of displacing the excessive fertiliser demand, energy recovery, and maturity in comparison with HTL process. However, HTL is a new evolving and promising nutrient recycling process which demonstrates economic preferences compared to AD process due to the low cost of production.

\section{Sensitivity analysis}

A sensitivity analysis is performed to identify components of the integrated biorefinery system that affect the net energy requirements and GWP and to further guide research. The sensitivity analysis is performed by independently varying each system parameter by $\pm 10 \%$ using the optimised conditions obtained in the present study. Results from the sensitivity to process parameters are presented for the full-scale scenario of both AD and HTL nutrient recycling technology and these are shown in Figure 7. In this investigation, the sensitivity of nutrient recycling efficiency of nitrogen and phosphorus is not studied. The increasing lipid content by $10 \%$ from baseline decreases EROI of the integrated system by $3 \%$ due to the decrease in the amount of mass (lipid exacted algae) going to the AD. This, in turn, decreases the electricity generated by co-processing of lipid extracted algae in the digester which leads to decrease in EROI. The increasing both the methane yield and volatile solid content has the increasing effect on the EROI. The results also show that increasing algal growth productivity has a minimal increasing effect on GWP. This is because when the productivity yield is increased, more electricity is required which increases usage of fossil fuel and GHG emissions accordingly. This result is consistent with the work of Quinin et al. ${ }^{41}$. The $10 \%$ increasing lipid content from baseline decreases GWP of the system by $13 \%$ and the $10 \%$ decreasing lipid content increases GWP of the system by $16 \%$. The increasing lipid content will decrease the amount of lipid extracted biomass fed to the AD which in turn decreases the amount of energy that can be produced by AD. This leads to the decrease in GHG emissions. The increasing both methane yield and volatile solid content have a positive effect on GWP. 
In HTL recycling technology, the parameters that influence EROI and GWP are biocrude yield and lipid content of algal biomass. The results show that both bio crude yield and lipid

content are more sensitive. This is consistent with the work by Fortier et al. ${ }^{42}$.It is found that the increasing both biocrude yield and lipid content by $10 \%$ from baseline increases the EROI by $11 \%$ and $2 \%$ respectively. The HTL recycling technology also shows that the increasing lipid content decreases GWP of the system by $13 \%$ and the decreasing lipid content increases GWP by $16 \%$ which is similarly found in AD recycling technology. The biocrude yield also impacts GWP significantly. There is minimal difference in GWP when both algal growth productivity and $\mathrm{CO}_{2}$ utilisation efficiency changes by $\pm 10 \%$.

The analysis of cost uncertainty is also performed for both AD and HTL nutrient recycling technology in this study and the results are shown in Figure 8. It is observed that most sensitive parameters that affect the annual profit of the integrated biorefinery system are the selling price of biodiesel and electricity. In AD case, the increasing a selling price of biodiesel by $10 \%$ from baseline increases the annual profit by $8.7 \%$, whereas in HTL, the annual profit increases by $11.4 \%$. The sensitivity of electricity selling price shows high in AD case $(5 \%)$ than that in HTL case $(0.43 \%)$. This is because AD generates more electricity. In both cases, the sensitivity of the cost of both water and hexane shows a minimal effect on the annual profit, whereas the nutrient cost (ammonia and phosphorous) shows a negligible effect due to its recycling.

\section{Discussion}

The findings from this modelling study are based on the engineering calculations and the reported values in the literature as well as laboratory scale experiments. Thus, future studies with additional data from the pilot or industrial-scale tests are required for the successful nutrient recycle technology to the integrated biofuel production from microalgae. Also, various scenarios are investigated in this work for possible future achievements and may not 
indicate the full status of commercial algal biofuel technology. Because various technical and environmental challenges still persist to realise the commercial production. The productivity levels and some parameters used in the description of scenarios are only 'theoretical' and 'maximum' as there is no clear evidence or report that such productivities are achievable or can be sustained over a period of time for the large-scale commercial production. Most of the projections made for algal biofuels are very excessive optimistic assumptions. The optimisation modelling is limited to consider on-site energy cost and nutrient recycling potential analysis, and it does not take into consideration the additional expenses of feedstock processing, logistics, and transport infrastructures. Also, since it is very challenging to identify the breakthrough in yield and cost saving in algal technology, incorporating a subsidy for GHG reductions has significantly increased the potential profitability of the hypothetical bio-refinery. Without this, algal biofuels are not likely to be competitive in the nearby future.

\section{CONCLUSION}

A case study of a hypothetical integrated biofuel system using nutrient recycling pathways of AD and HTL is presented through multi-objective optimisation. Three different scenarios are considered based on the levels of future maturity. The solution of the optimisation problems produces Pareto sets of optimal solutions that can be used to acknowledge the compromise (trade-off) between the economic and the environmental criteria of the integrated system. The results show that AD or HTL nutrient recycling technology can be integrated with the algal biofuel production system and thus utilised to reduce the cost and environmental implications of algal biofuels. Also, it is found that the AD technology shows much better performance in terms of displacing the excessive fertiliser demand, energy recovery, GHG emissions reduction, and maturity compared to HTL process. However, HTL is a new 
evolving and promising nutrient recycling process which demonstrates economic preferences compared to AD process. For recommending HTL or AD as effective nutrient recycling pathways, more research is needed in pilot and demonstration-scale.

\section{ACKNOWLEDGEMENT}

Author (PR) thanks to DST, India for the financial support by DST INSPIRE Faculty Award (DST/INSPIRE/2014/ENG-97). Author (MB) gratefully acknowledged the financial support for this work by Petroleum Technology Development Fund (PTDF) award, Nigeria (PTDF/E/OSS/PHD/MB/407/11),

\section{Appendix A: supplementary data}

Supplementary material related to this article is included.

\section{REFERENCES}

(1) Jegathese, S.; Farid, M. Microalgae as a renewable source of energy: A niche opportunity. J. Renew Energy 2014, No. 430203

(2)Venteris, E. R.; Skaggs, R. L.; Wigmosta, M. S.; Coleman, A. M. A national-scale comparison of resource and nutrient demands for algae-based biofuel production by lipid extraction and hydrothermal liquefaction. Biomass Bioenergy 2014, 64, 276-290.

(3) Slade, R.; Bauen, A. Micro-algae cultivation for biofuels: Cost, energy balance, environmental impacts and future prospects. Biomass Bioenergy 2013, 53, 29-38.

(4) Lardon, L.; Hélias, A.; Sialve, B.; Steyer, J.; Bernard, O. Life-cycle assessment of biodiesel production from microalgae. Environ. Sci. Technol. 2009, 43, 6475-6481.

(5) Stephenson, A. L.; Kazamia, E.; Dennis, J. S.; Howe, C. J.; Scott, S. A.; Smith, A. G.. Life-cycle assessment of potential algal biodiesel production in the United Kingdom: A comparison of raceways and air-lift tubular bioreactors. Energy Fuels 2010, 24, 4062-4077. 
(6) Handler, R. M.; Canter, C. E.; Kalnes, T. N.; Lupton, F. S.; Kholiqov, O.; Shonnard, D.R.; Blowers, P. Evaluation of environmental impacts from microalgae cultivation in openair raceway ponds: Analysis of the prior literature and investigation of wide variance in predicted impacts. Algal Res. 2012, 1, 83-92.

(7) Yang, J.; Xu, M.; Zhang, X.; Hu, Q.; Sommerfeld, M.; Chen, Y. Life-cycle analysis on biodiesel production from microalgae: Water footprint and nutrients balance. Bioresour. Technol. 2011, 102, 159-165.

(8) Sills, D. L.; Paramita, V.; Franke, M. J.; Johnson, M. C.; Akabas, T. M.; Greene, C. H.; Tester, J. W. Quantitative uncertainty analysis of life cycle assessment for algal biofuel production. Environmental sci. Technol. 2012, 47, 687-694.

(9) Johnson, M. C.; Palou-Rivera, I.; Frank, E. D. Energy consumption during the manufacture of nutrients for algae cultivation. Algal Res. 2013, 2, 426-436.

(10) Mayers, J. J.; Flynn, K. J.; Shields, R. J. Influence of the N: P supply ratio on biomass productivity and time-resolved changes in elemental and bulk biochemical composition of Nannochloropsissp. Bioresour. Technol. 2014, 169, 588-595.

(10) Wigmosta M. S.; Coleman A. M.; Skagss R. J.; Huesemen M. H.; Lane I.J. National Microalgae biofuel production potential and resource demand. Water Resour. Res. 2011, 47, $1-13$.

(12) Pate, R.; Klise, G.; Wu, B. Resource demand implications for US algae biofuels production scale-up. Appl. Energy 2011, 88, 3377-3388.

(13) Quinn, J. C.; Yates, T.; Douglas, N.; Weyer, K.; Butler, J.; Bradley, T. H.; Lammers, P. J. Nannochloropsis production metrics in a scalable outdoor photobioreactor for commercial applications. Bioresour. Technol. 2012, 117, 164-171. 
(14) Gutiérrez-Arriaga, C. G.; Serna-González, M.; Ponce-Ortega, J. M.; El-Halwagi, M.

M. Sustainable integration of algal biodiesel production with steam electric power plants for greenhous gas mitigation. ACS Sustainable Chem. Eng. 2014, 2, 1388-1403.

(15) Vardon, D. R.; Sharma, B. K.; Blazina, G. V.; Rajagopalan, K.; Strathmann, T. J.

Thermochemical conversion of raw and defatted algal biomass via hydrothermal liquefaction and slow pyrolysis. Bioresour.Technol. 2012, 109, 178-187.

(16) Sialve, B.; Bernet, N.; Bernard, O. Anaerobic digestion of microalgae as a necessary step to make microalgal biodiesel sustainable. Biotechnol. Adv. 2009, 27, 409-416.

(17) Collet, P.; Hélias, A.; Lardon, L.; Ras, M.; Goy, R.; Steyer, J. Life-cycle assessment of microalgae culture coupled to biogas production. Bioresour. Technol. 2011, 102, 207-214. (18) Frank, E. D.; Han, J.; Palou-Rivera, I.; Elgowainy, A.; Wang, M. Q. Methane and nitrous oxide emissions affect the life-cycle analysis of algal biofuels. Environ. Res. Lett. 2012, 7, 1-10.

(19) Beal, C. M.; Hebner, R. E.; Webber, M. E.; Ruoff, R. S.; Seibert, A. F.; King, C. W. Comprehensive evaluation of algal biofuel production: experimental and target results. Energies 2012, 5, 1943-1981.

(20) Gerber, L. N. H.; Tester, J. W.; Beal, C. M.; Huntley, M.; Sills, D. L. Target cultivation and financing parameters for sustainable production of fuel and feed from microalgae. Environ. Sci. Technol. 2016, 49, 3333-3341

(21) Zhang, Y.; Kendall, A.; Yuan, J. A. Comparison of on-site nutrient and energy recycling technologies in algal oil production. Resour. Conserv Recy. 2014, 88, 13-20.

(22) Biller, P.; Ross, A. B.; Skill, S. C.; Lea-Langton, A.; Balasundaram, B.; Hall, C.; Riley, R.; Llewellyn, C. A. Nutrient recycling of aqueous phase for microalgae cultivation from the hydrothermal liquefaction process. Algal Res. 2012, 1, 70-76. 
(23) Naik, S. N.; Goud, V. V.; Rout, P. K.; Dalai, A. J. Production of first and second generation biofuels: A comprehensive review. Renew. Sustainable Energy Rev. 2010, 14, $578-597$.

(24) Jena, U.; Vaidyanathan, N.; Chinnasamy, S.; Das, K.C. Evaluation of microalgae cultivation using recovered aqueous co-product from thermochemical liquefaction of algal biomass. Bioresour.Technol. 2011,102, 3380-3387.

(25) Valdez, P. J.; Nelson, M. C.; Wang, H. Y.; Lin, X. N.; Savage, P. E. Hydrothermal liquefaction of Nannochloropsis sp.: Systematic study of process variables and analysis of the product fractions. Biomass Bioenergy 2012, 46, 317-331.

(26) Gebreslassie, B. H.; Waymire, R.; You, F. Sustainable design and synthesis of algaebased biorefinery for simultaneous hydrocarbon biofuel production and carbon sequestration. AIChE J. 2013, 59, 1599-1621.

(27) Ventura, J. S.; Yang, B.; Lee, Y.; Lee, K.; Jahng, D. Life cycle analyses of CO2, energy, and cost for four different routes of microalgal bioenergy conversion. Bioresour.Technol. 2013, 137, 302-310.

(28) Bauer, A.; Mayr, H.; Hopfner-Sixt, K.; Amon, T. Detailed monitoring of two biogas plants and mechanical solid-liquid separation of fermentation residues. J. Biotechnol. $\mathbf{2 0 0 9 , 1 4 2 , 5 6 - 6 3 . ~}$

(29) Davis, R.; Fishman, D.; Frank, E.; Wigmosta, M.; Aden, A.; Coleman, A.; Pienkos, P.; Skaggs, R.; Venteris, E.; Wang, M. Renewable Diesel from Algal Lipids: An Integrated Baseline for Cost, Emissions, and Resource Potential from a Harmonized Model. Argonne National Laboratory, 2012.

(30) Lundquist, T. J.; Woertz, I.; Benemann, J. R. Microalgae for wastewater treatment and biofuels production; ACS National Meeting Book of Abstracts, 2010. 
(31) Frank, E.; Han, J.; Palou-Rivera, I.; Elgowainy, A.; Wang, M. Methane and nitrous oxide emissions affect the life-cycle analysis of algal biofuels. Environ. Res. Lett. 2012, 7, 014030.

(32) Sheehan, J.; Dunahay, T.; Benemann, J.; Roessler, P. A look back at the US Department of Energy's aquatic species program: biodiesel from algae; the National Renewable Energy Laboratory: Goldon, CO, 1998.

(33) Frank, E. D.; Elgowainy, A.; Han, J.; Wang, Z. Life cycle comparison of hydrothermal liquefaction and lipid extraction pathways to renewable diesel from algae. Mitig. Adapt. Strat. Gl. 2013, 18, 137-158.

(34) López Barreiro, D.; Prins, W.; Ronsse, F.; Brilman, W. Hydrothermal liquefaction (HTL) of microalgae for biofuel production: State of the art review and future prospects. Biomass Bioenergy 2013, 53, 113-127.

(35) Chisti, Y. Biodiesel from microalgae. Biotechnol. Adv. 2007, 25, 294-306.

(36) Liu, X.; Saydah, B.; Eranki, P.; Colosi, L. M.; Mitchell, B. G.; Rhodes, J.; Clarens, A. Pilot-scale data provide enhanced estimates of the life cycle energy and emissions profile of algae biofuels produced via hydrothermal liquefaction. Bioresour. Technol. 2013, 148, $163-171$

(37) IPCC Climate Change 2007; The Physical Science Basis: Contribution of Working Group I to the Fourth Assessment Report of the Intergovernmental Panel on Climate Change, Cambridge University Press: Cambridge, United Kingdom, 2007.

(38) Goedkoop, M.; de Schryver, A.; Oele, M.; Durksz, S.; De Roest, D. Introduction to LCA with SimaPro 7. Report Version 4.4. Pre Consultants, Creative Commons: San Francisco, USA, 2010.

(39) Gong, J.; You, F. Value-added chemcials from microalage: Greener, More economical or both. ACS Sustainable Chem. Eng. 2015, 3, 82-96. 
(40) Delrue, F.; Li-Beisson, Y.; Setier, P.; Sahut, C.; Roubaud, A.; Froment, A.; Peltier, G. Comparison of various microalgae liquid biofuel production pathways based on energetic, economic and environmental criteria. Bioresour.Technol. 2013,136, 205-212.

(41) Quinn, J.C.; Smith, T.G.; Downes, C.M.; Quinn, C. Microalgae to biofuels lifecycle assessment-multiple pathway evaluation. Algal. Res. 2014, 4,116-122.

(42) Fortier, M.-O. P.; Roberts, G. W.; Stagg-Williams, S. M.; Sturm, B. S. M. Life cycle assessment of bio-jet fuel from hydrothermal liquefaction of microalgae. Appl. Energy 2014, $122,73-82$ 


\section{Table list}

Table 1: List of selected parameters and three different scenarios of AD and HTL for hypothetical integrated algal biodiesel production

\begin{tabular}{|c|c|c|c|c|c|c|c|c|}
\hline \multicolumn{2}{|c|}{ Biofuel Production } & \multicolumn{3}{|c|}{ AD Scenario } & \multicolumn{3}{|c|}{ HTL Scenario } & \multirow[b]{2}{*}{ Reference } \\
\hline Parameter & Unit & $\begin{array}{c}\text { Baseline } \\
\text { (Commerc } \\
\text { ial) } \\
\end{array}$ & $\begin{array}{c}\text { Conservative } \\
\text { (demonstration) }\end{array}$ & $\begin{array}{c}\text { Nominal } \\
\text { (Lab- } \\
\text { scale) } \\
\end{array}$ & $\begin{array}{l}\text { Baseline } \\
\text { (Commerc } \\
\text { ial) } \\
\end{array}$ & $\begin{array}{c}\text { Conservative } \\
\text { (demonstration) }\end{array}$ & $\begin{array}{c}\text { Nominal } \\
\text { (Lab-scale) }\end{array}$ & \\
\hline N Recovery & $\%$ & 86 & 76 & 50 & 84 & 70 & 15 & $\begin{array}{l}\text { Bauer et al. }{ }^{28} \\
\text { Davis et al. }{ }^{29} \\
\text { Frank et al. }{ }^{18} \\
\text { Venteris et al. }{ }^{2}\end{array}$ \\
\hline P Recovery & $\%$ & 85 & 49 & 9 & 85 & 28.3 & 20 & $\begin{array}{l}\text { Bauer et al. }{ }^{28} \\
\text { Davis et al. }{ }^{29} \\
\text { Frank et al. }{ }^{18} \\
\text { Venteris et al. }\end{array}$ \\
\hline $\begin{array}{l}\text { C utilization } \\
\text { efficiency }\end{array}$ & $\%$ & 90 & 85 & 80 & 90 & 85 & 80 & $\begin{array}{l}\text { Lundquist et al. }^{30} \\
\text { Frank et al. }^{31} \\
\text { Quinn et al. }{ }^{13} \\
\text { Sheehan et al. } \\
\end{array}$ \\
\hline $\begin{array}{l}\mathrm{CH}_{4} \\
\text { theoretical } \\
\text { yield }\end{array}$ & $\mathrm{L} / \mathrm{g}$ VS & 0.80 & 0.66 & 0.4 & - & - & - & $\begin{array}{l}\text { Sialve et al. }{ }^{16} \\
\text { Zhang et al. }{ }^{21} \\
\text { Frank et al. }{ }^{33} \\
\end{array}$ \\
\hline $\begin{array}{l}\text { Bio-crude } \\
\text { yield }\end{array}$ & wt $\%$ & - & - & - & 35.4 & 35.3 & 35.3 & $\begin{array}{l}\text { Vardon et al. } \\
\text { López Barreiro et } \\
\text { al. }^{34}\end{array}$ \\
\hline $\begin{array}{l}\mathrm{C}: \mathrm{N}: \mathrm{P} \text { mol. } \\
\text { ratio }\end{array}$ & & $175: 21: 1$ & 100:9:1 & 106:16:1 & $175: 21: 1$ & 100:9:1 & 106:16:1 & $\begin{array}{l}\text { Chisti }^{35} \\
\text { Frank et al. }^{33}\end{array}$ \\
\hline Growth rate & $\mathrm{g} / \mathrm{m}^{2} / \mathrm{day}$ & 40 & 30 & 25 & 40 & 30 & 25 & $\begin{array}{l}\text { Chisti }^{35} \\
\text { Frank et al. }^{33} \\
\text { Frank et al. }^{31} \\
\text { Gutiérrez-Arriaga et } \\
\text { al. }^{14}\end{array}$ \\
\hline Lipid content & & 40 & 30 & 25 & 40 & 30 & 25 & $\begin{array}{l}\text { Zhang et al. }{ }^{20} \\
\text { Gutiérrez-Arriaga et } \\
\text { al. }{ }^{14} \\
\text { Frank et al. }{ }^{31}\end{array}$ \\
\hline $\begin{array}{l}\text { Volatile solids } \\
\text { (VS) }\end{array}$ & $\begin{array}{l}\% \text { total } \\
\text { solid } \\
(\mathrm{TS})\end{array}$ & 90.2 & 90 & 80.5 & 90.2 & 90 & 80.5 & $\begin{array}{l}\text { Sialve et al. }{ }^{16} \\
\text { Collet et al. }{ }^{17}\end{array}$ \\
\hline
\end{tabular}


Table 2: Modelling results of the profit and environmental impact for various scenarios using a unit subsidy of $\$ 20 /$ tonne $\mathrm{CO}_{2}$ eq.

\begin{tabular}{cccccc}
\hline \multirow{2}{*}{$\begin{array}{c}\text { Technology } \\
\text { pathway }\end{array}$} & Scenarios & \multicolumn{2}{c}{ Profit (US\$/yr MM) } & \multicolumn{2}{c}{$\begin{array}{c}\text { GWP (gCO } \mathbf{2}^{-} \\
\text {equiv./MJ) }\end{array}$} \\
\cline { 3 - 6 } & & Max & Min & Max & Min \\
\hline \multirow{2}{*}{ AD } & Full-scale & 3.64 & 0.09 & 59.8 & 46.7 \\
\cline { 2 - 6 } & Pilot-scale & 1.8 & -0.0016 & 69.2 & 57.5 \\
\cline { 2 - 6 } & Lab-scale & 0.361 & -0.0084 & 47.7 & 41.4 \\
\hline \multirow{2}{*}{ HTL } & Full-scale & 2.2 & 0.35 & 31.2 & 28.5 \\
\cline { 2 - 6 } & Pilot-scale & 0.96 & 0.02 & 44.6 & 42.1 \\
\cline { 2 - 6 } & Lab-scale & 0.50 & -0.009 & 54.4 & 53.2 \\
\hline
\end{tabular}


Table 3: A comparison betweetn AD and HTL in terms of nutrient recycling and energy production for the hypothetical integrated bio-refinery system

\begin{tabular}{|c|c|c|c|}
\hline Parameter & Unit & AD & HTL \\
\hline Algal biomass & tonne/yr. & 14304 & 14304 \\
\hline Residual biomass & tonne/yr. & 80195 & 80195 \\
\hline Make-up water & tonne/yr. & $1.7946 \times 10^{7}$ & $9.05 \times 10^{3}$ \\
\hline Biodiesel production & tonne/yr. & 3773.9 & 3773.9 \\
\hline Glycerol production & tonne/yr. & 415 & 415 \\
\hline Bio-crude production & tonne/yr. & - & 3208 \\
\hline $\begin{array}{l}\text { Bio-methane } \\
\text { production }\end{array}$ & tonne/yr. & $3.1249 \times 10^{9}$ & - \\
\hline $\begin{array}{l}\text { Electricity generation } \\
\text { from bio-crude }\end{array}$ & $\mathrm{MJ} / \mathrm{yr}$. & $4.241 \times 10^{7}$ & $1.019 \times 10^{7}$ \\
\hline $\begin{array}{l}\text { Heat generation from } \\
\text { bio-crude }\end{array}$ & $\mathrm{MJ} / \mathrm{yr}$. & $5.890 \times 10^{7}$ & $7.926 \times 10^{7}$ \\
\hline $\begin{array}{l}\text { Total power } \\
\text { produced }\end{array}$ & MJ/year & $1.1691 \times 10^{8}$ & $8.9729 \times 10^{7}$ \\
\hline $\begin{array}{l}\text { Total power } \\
\text { consumed }\end{array}$ & MJ/year & $6.6913 \times 10^{7}$ & $8.7042 \times 10^{7}$ \\
\hline $\begin{array}{l}\text { Average Nitrogen } \\
\text { recycled }\end{array}$ & tonne/yr. & 2.94 & 1.08 \\
\hline $\begin{array}{l}\text { Average Phosphorous } \\
\text { recycled }\end{array}$ & tonne/yr. & 4.7 & 1.1 \\
\hline $\begin{array}{l}\text { Overall Nitrogen } \\
\text { demand }\end{array}$ & tonne/yr. & 404 & 401 \\
\hline $\begin{array}{l}\text { Overall Phosphorous } \\
\text { demand }\end{array}$ & tonne/yr. & 90.5 & 86.9 \\
\hline $\begin{array}{l}\text { GHG reduction by } \mathrm{N} \\
\text { recycling }\end{array}$ & $\mathrm{g} \mathrm{CO}_{2}$ eq./MJ & 4.59 & 4.57 \\
\hline $\begin{array}{l}\text { GHG reduction by } \mathrm{P} \\
\text { recycling }\end{array}$ & $\mathrm{g} \mathrm{CO}_{2}$ eq./MJ & 0.49 & 0.47 \\
\hline $\begin{array}{l}\text { GHG reduction by } \\
\text { electricity generation }\end{array}$ & $\mathrm{g} \mathrm{CO}_{2}$ eq./MJ & 53.79 & 12.93 \\
\hline $\begin{array}{l}\text { GHG reduction by } \\
\text { heat generation }\end{array}$ & $\mathrm{g} \mathrm{CO}_{2}$ eq./MJ & 33.9 & 45.61 \\
\hline Direct GHG emission & $\mathrm{g} \mathrm{CO}_{2}$ eq./MJ & 46.39 & 31.8 \\
\hline $\begin{array}{l}\text { GHG emission by } \\
\text { power consumption }\end{array}$ & $\mathrm{g} \mathrm{CO}_{2}$ eq./MJ & 6.53 & 1.55 \\
\hline Total GHG emission & $\mathrm{g} \mathrm{CO}_{2}$ eq./MJ & 52.93 & 33.35 \\
\hline
\end{tabular}




\section{Figures}

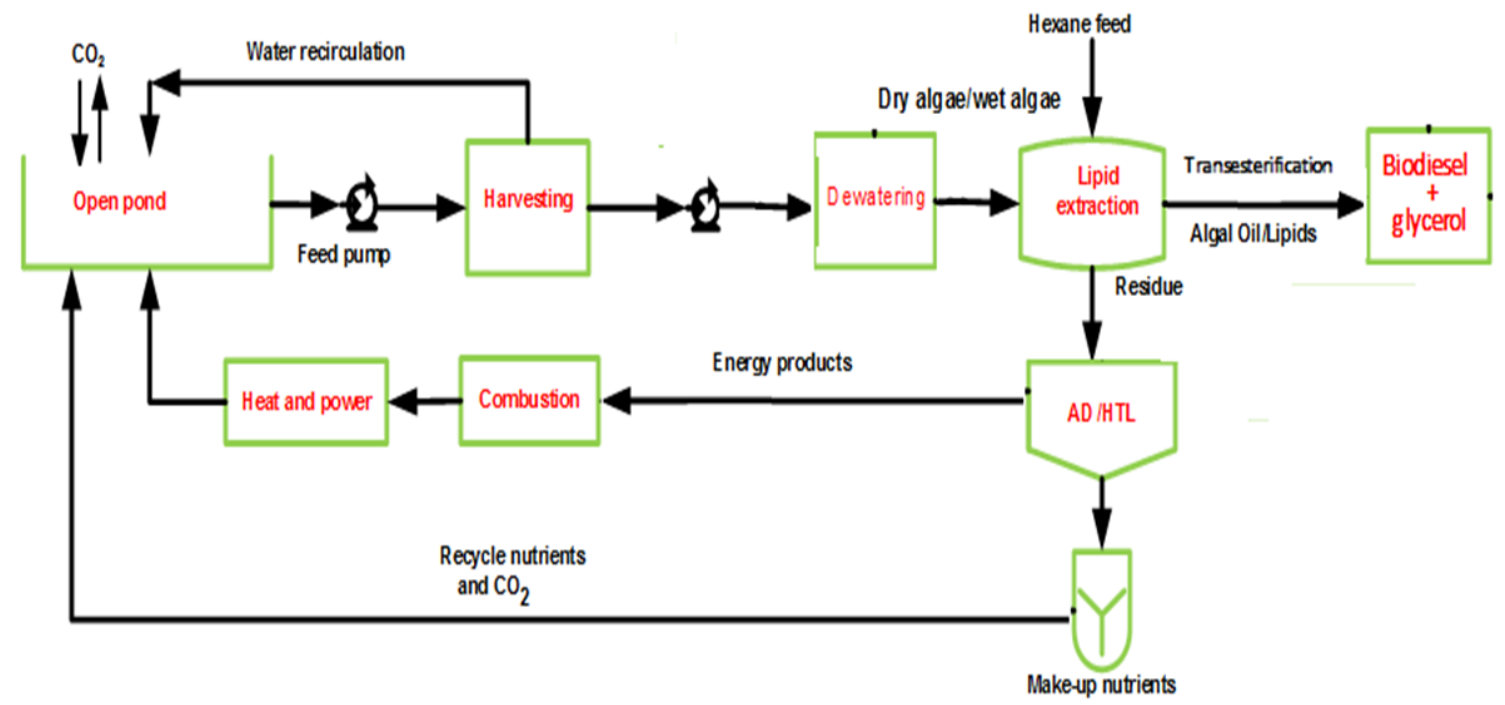

Figure 1: A hypothetical integrated microalgae bio-refinery using AD/HTL recycling technology

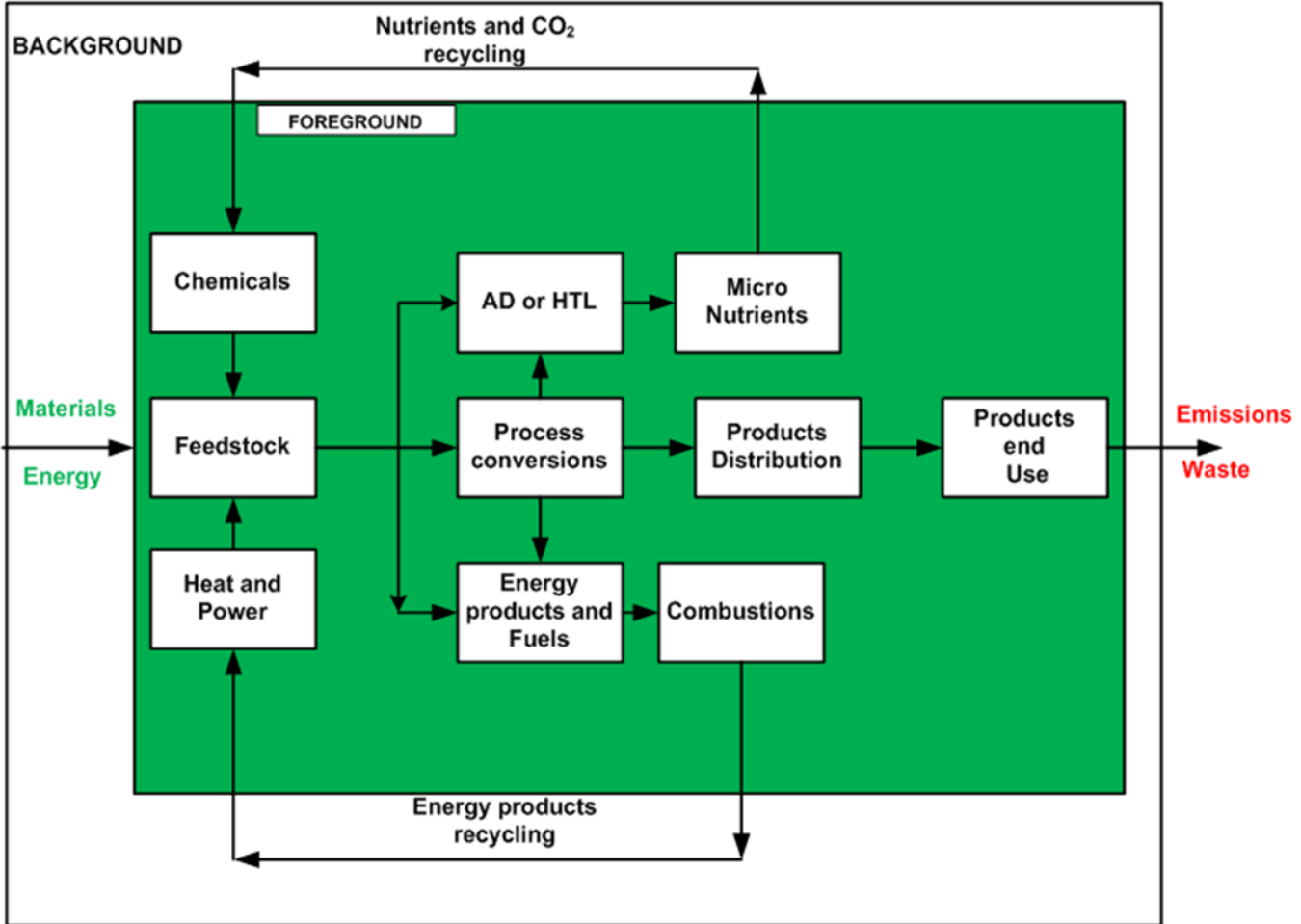

Figure 2: A system boundary for life cycle stages of the hypothetical bio-refinery 


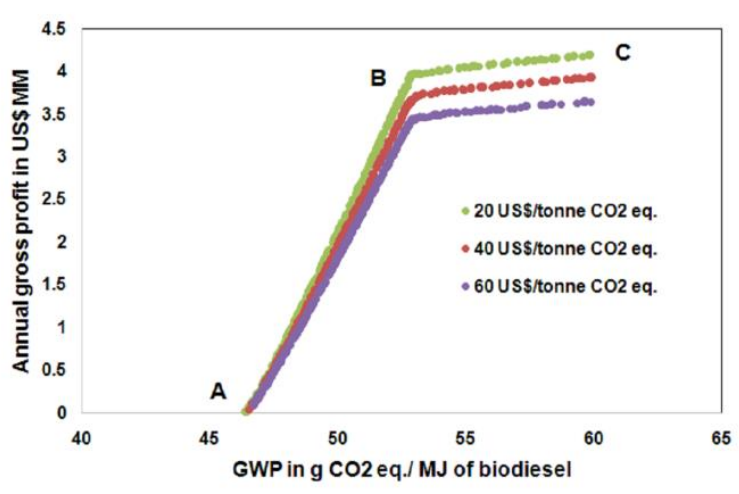

(a)

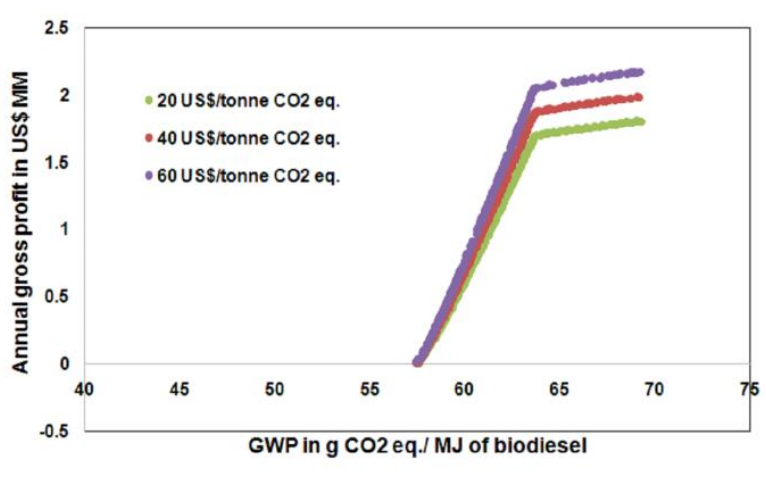

(b)

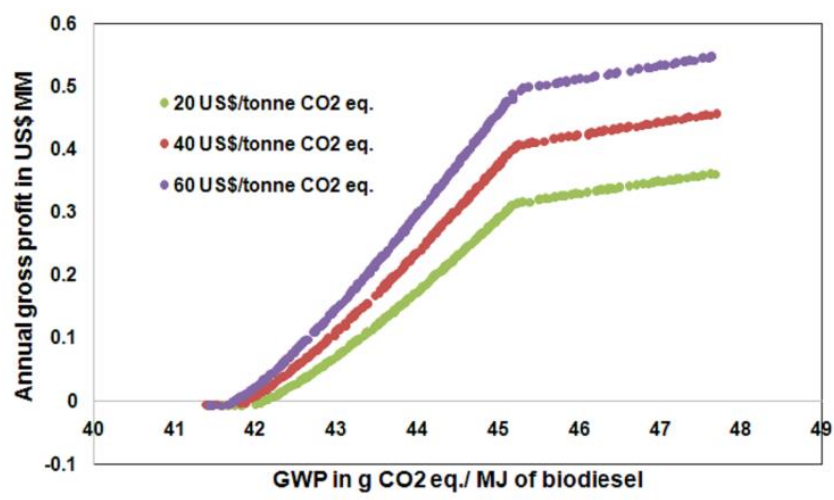

(C)

Figure 2: Pareto-curves for the hypothetical integrated biofuel system using AD recycling technology with different subsidy units demonstrated at (a) baseline scenario (b) conservative Scenario (c) nominal scenario

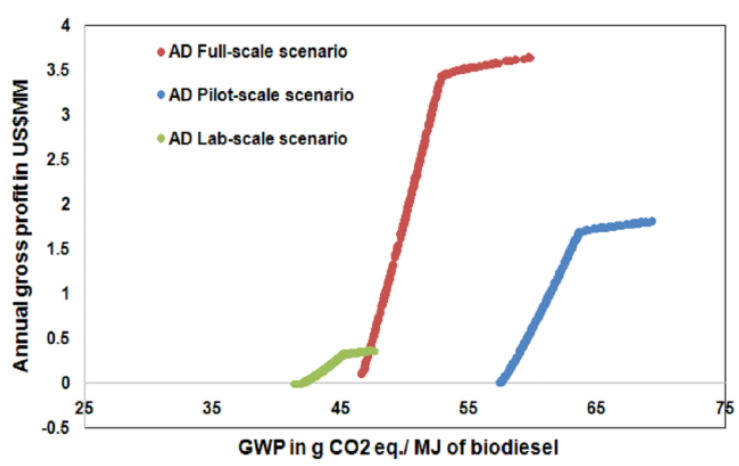

(a)

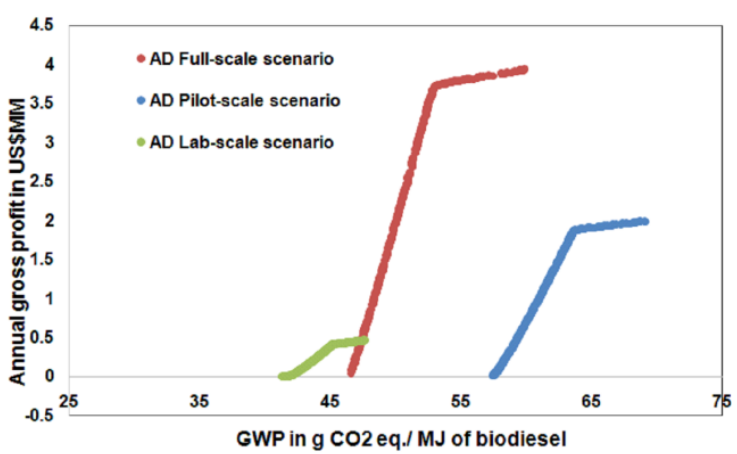

(b)

Figure 4: Pareto-curves for the hypothetical integrated biofuel system using different scenarios of AD recycling technology with different subsidy unit of (a) $20 \mathrm{US} \$ /$ tonne $\mathrm{CO}_{2}$ equivalent (b) $40 \mathrm{US} \$ /$ tonne $\mathrm{CO}_{2}$ equivalent 


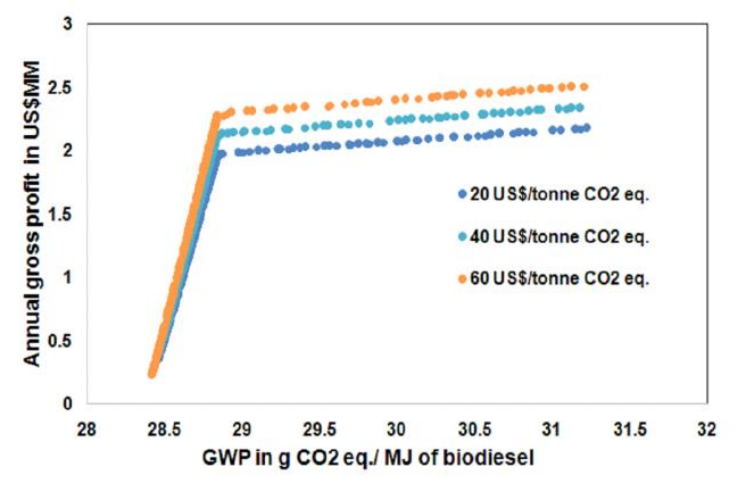

(a)

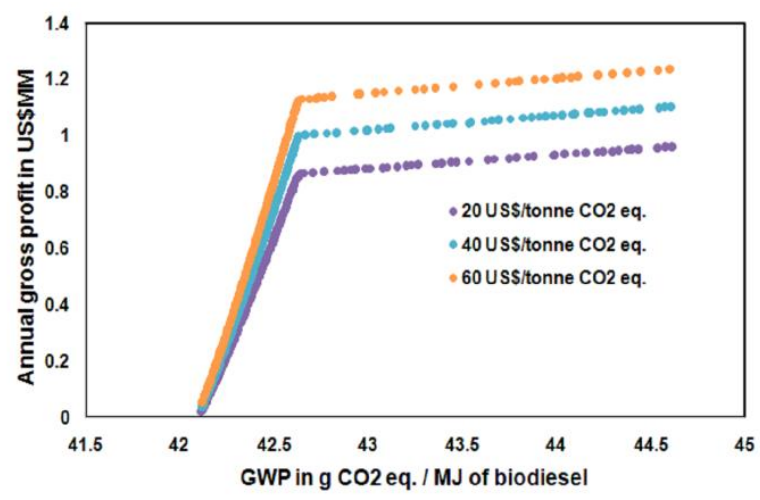

(b)

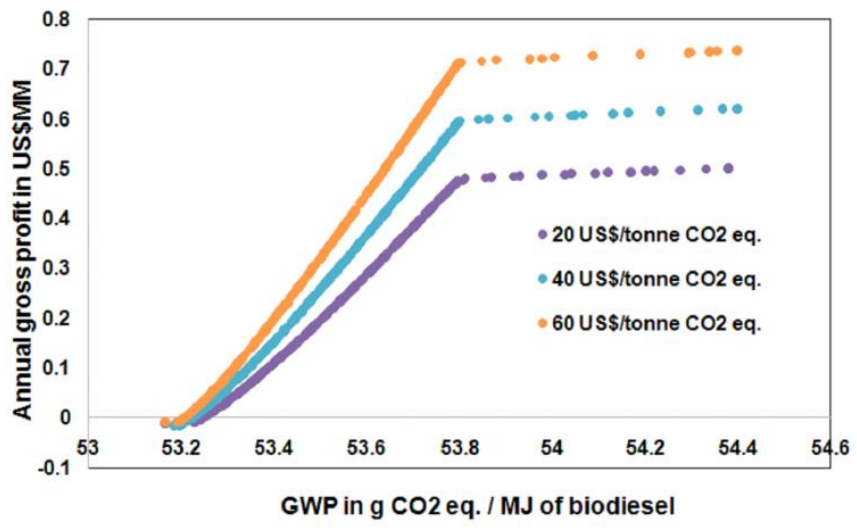

(C)

Figure 5: Pareto-curves for the hypothetical integrated biofuel system using HTL recycling technology with varies subsidy units for GHG emissions reduction demonstrated at (a) baseline scenario (b) conservative Scenario (c) nominal scenario

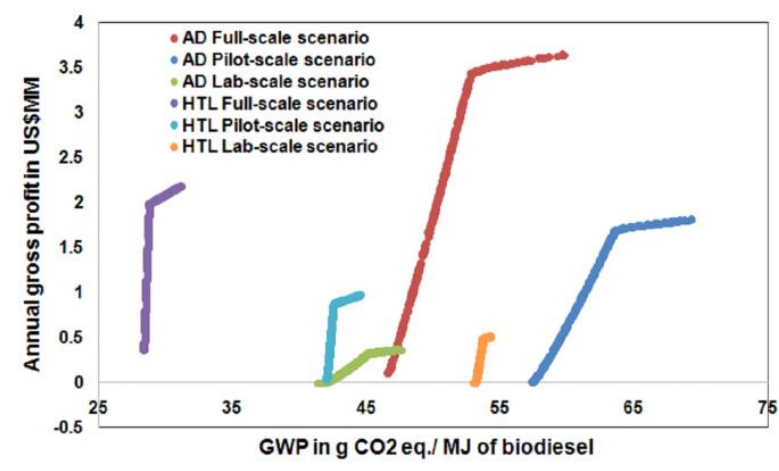

(a)

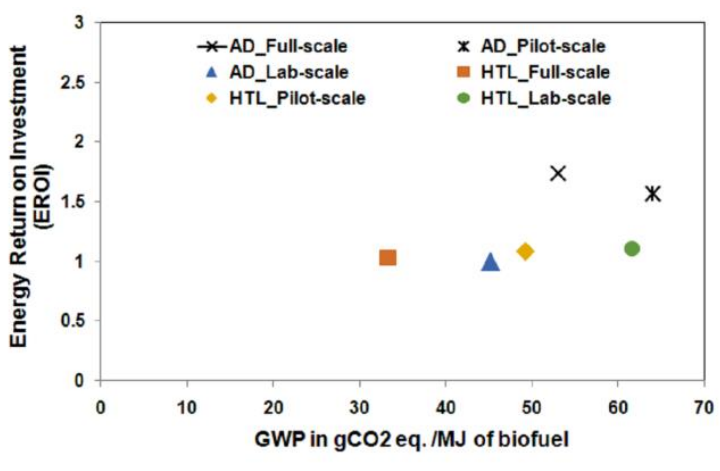

(b)

Figure 6: (a) A comparison plot of Pareto-curves between AD and HTL recycling technology for different scenarios at a particular subsidy unit of $20 \mathrm{US} \$ /$ tonne $\mathrm{CO}_{2}$ 
equivalent (b) EROI vs. GWP plot for different scenarios of both AD and HTL recycling technology
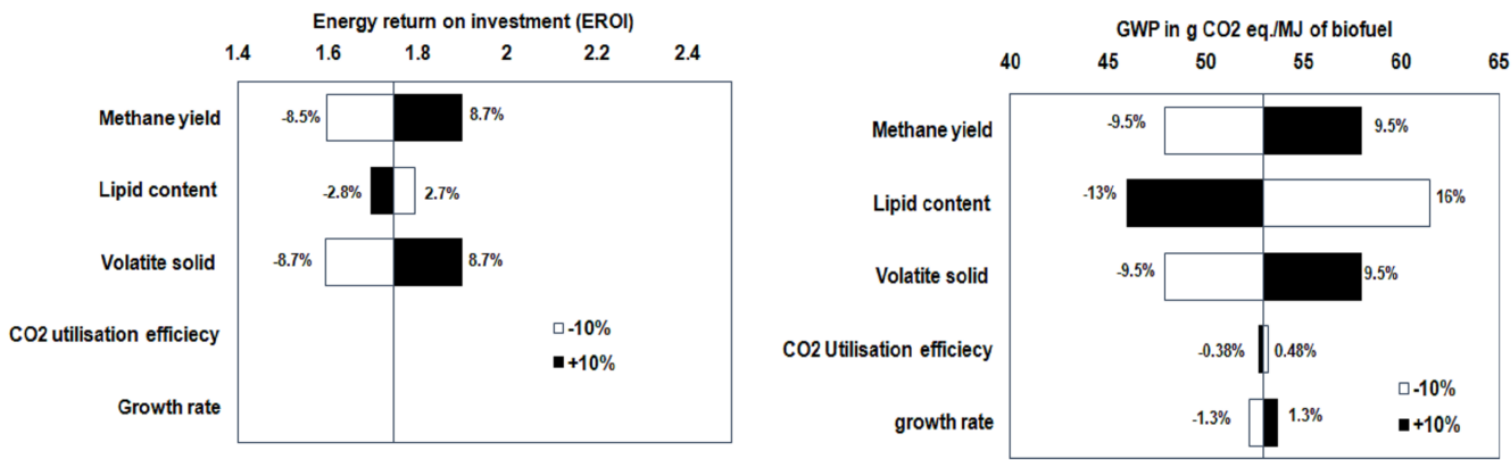

(a) AD nutrient recycling technology
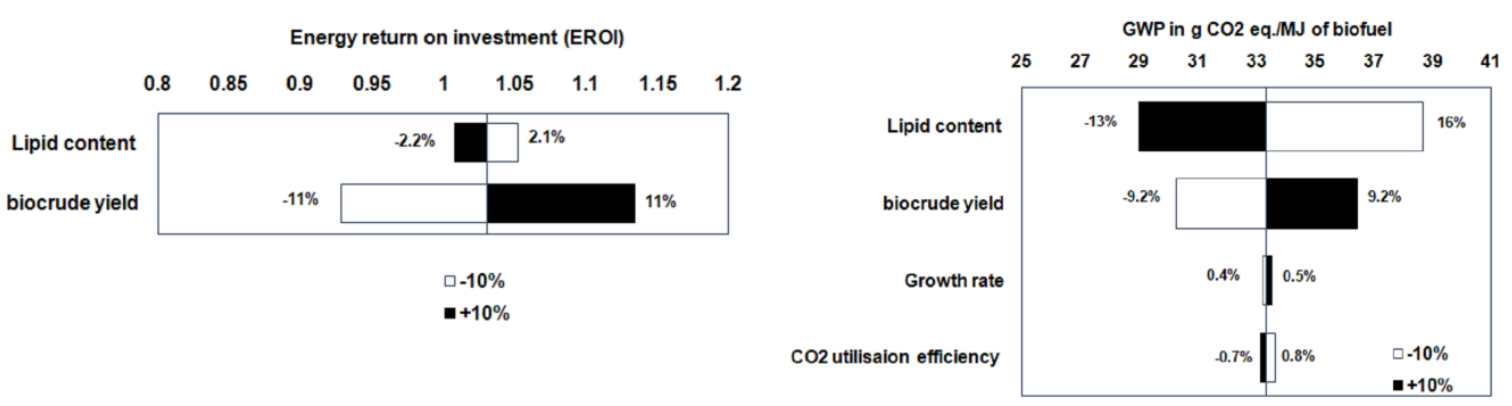

(b) HTL nutrient recycling technology

Figure 7: Sensitivity analysis of the hypothetical bio-refinery system using (a) AD recycling technology (b) HTL recycling technology

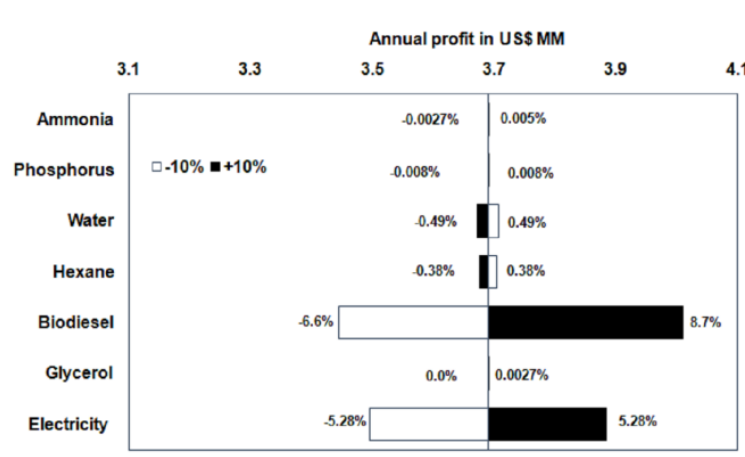

(a) AD nutrient recycling technology

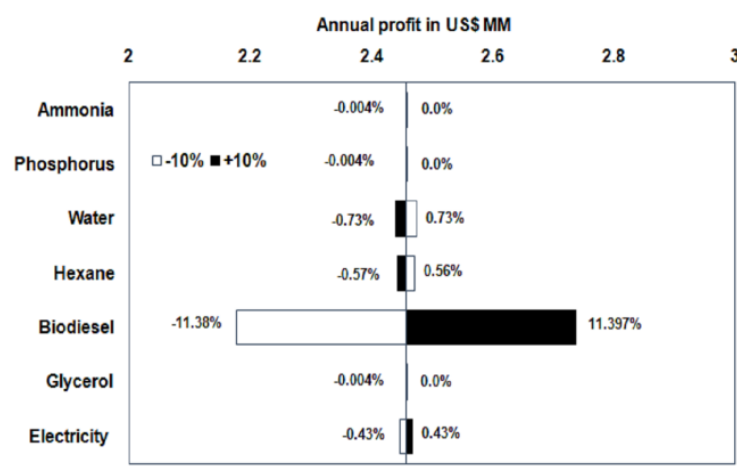

(b) HTL nutrient recycling technology

Figure 8: Cost uncertainty analysis of the hypothetical bio-refinery system using (a) AD (b) HTL recycling technology 


\section{For Table of Contents Use Only}

Sustainable process of algal biofuel production by the integration of nutrient recycling of AD and HTL is studied using multi-objective optimisation method.

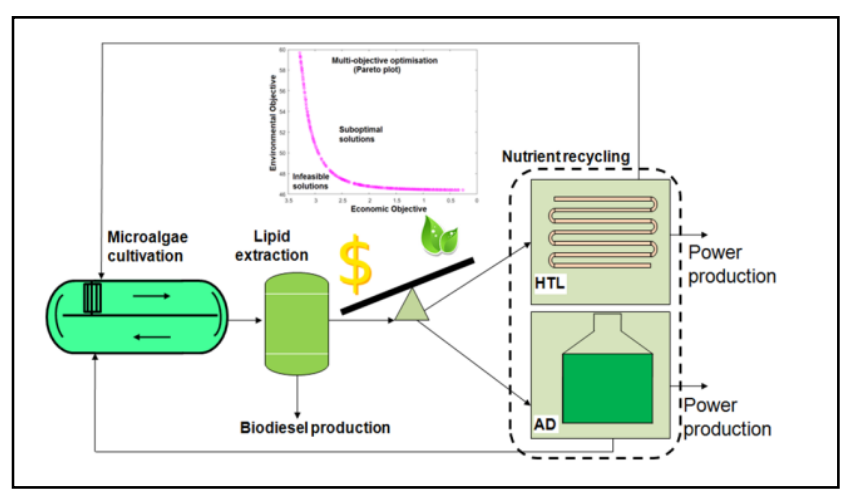

